\title{
Mecanismo de ação e reações adversas dos antivirais preconizados para hepatite $\mathrm{C}$ no Brasil
}

\author{
Mechanism of action and adverse reactions of antivirals recommended \\ for hepatitis C in Brazil
}

Recebido em: 02/01/2021 Aceito em: 18/02/2021
Jose Raul Rocha de ARAÚJO JÚNIOR ${ }^{1}$; Ariane Araújo de Carvalho da SILVA²; Simone Cristina Silva de SOUZA ${ }^{2}$ ${ }^{1}$ Instituto Evandro Chagas. Av. Alm. Barroso, 492, Bairro São Brás, CEP 66093-020. Belém, PA, Brasil. ${ }^{2}$ Escola Superior da Amazônia - ESAMAZ. R. Municipalidade, 546, Bairro Reduto, CEP 66053-18. Belém, PA,Brasil. E-mail:jraularaujo@hotmail.com

\section{ABSTRACT}

Hepatitis $\mathrm{C}$ is a disease that affects the entire world population, also affecting the population's quality of life. The use of medications is fundamental for the therapeutic process of patients with hepatitis $\mathrm{C}$. The treatment of hepatitis $\mathrm{C}$ faced several obstacles with the viral pangenotypic diversity and the adverse treatment reactions faced by those infected with the vírus. However, over the years, the evolution of the pharmaceutical market and antiviral drugs has occurred in several research fields against hepatitis $C$. In this context, it is important to understand the mechanisms of action and adverse reactions of the drugs used to treat hepatitis $\mathrm{C}$ in Brazil. The research is a bibliographic review, through a survey of scientific articles in the databases LILACs, Pubmed, Google Acadêmico, and SciELO, ordinances, and bulletins from the Ministry of Health. Molecular improvements of the drugs aim to decrease the treatment time, thus increasing patient compliance because these new drugs have mild adverse effects. Concerning the treatment of hepatitis $\mathrm{C}$, the pharmaceutical industry trend is to produce pangenotypic drugs, that is, that act in all HCV genotypes.

Keywords: Hepatitis C; pangenotypic drugs; antiviral drugs.

\section{RESUMO}

A hepatite $\mathrm{C}$ é uma doença que afeta toda população mundial, afetando também a qualidade de vida da população. O uso de medicamentos é fundamental para o processo terapêutico dos pacientes com hepatite C. O tratamento da hepatite $\mathrm{C}$ enfrentou diversos obstáculos com a diversidade pangenotípica viral e as reações adversas do tratamento enfrentadas pelos infectados com o vírus. Entretanto, com o decorrer dos anos, a evolução do mercado farmacêutico e dos medicamentos antivirais ocorreu em diversos campos da pesquisa contra a hepatite $\mathrm{C}$. Neste contexto se torna importante compreender os mecanismos de ação e reações adversas dos fármacos utilizados para o tratamento da hepatite $\mathrm{C}$ no Brasil. A pesquisa trata de uma revisão bibliográfica, por meio de levantamento de artigos científicos nas bases de dados LILACs, Pubmed, Google Acadêmico e SciELO, portarias e boletins do Ministério da Saúde. Melhorias moleculares dos 
fármacos visam diminuir o tempo de tratamento, aumentando assim a adesão do paciente, pelo fato desses novos medicamentos apresentarem efeitos adversos mais leves. A tendência da indústria farmacêutica, no que diz respeito ao tratamento da hepatite $\mathrm{C}$, é produzir medicamentos pangenotípicos, ou seja, que atuam em todos os genótipos do VHC.

Palavras-chave: Hepatite C; medicamento pangenotípico; fármaco antiviral.

\section{INTRODUÇÃO}

A hepatite C é causada pelo VHC, pertencente ao reino Riboviria, da ordem Nidovirales, da família Flaviviridae e gênero Hepacivirus (1). A hepatite $\mathrm{C}$ se manifesta clinicamente principalmente por lesões hepáticas. A maioria dos indivíduos infectados é assintomática e a evolução da doença está ligada diretamente a carga viral do vírus da hepatite $\mathrm{C}$ (VHC) presente no paciente (2).

O VHC é um vírus de RNA de fita simples, polaridade positiva, que contém, em seu material genético, aproximadamente 9.500 nucleotídeos. Possui envelope constituído de proteína, carboidrato e lipídeos e o capsídeo é icosaédrico. Sua partícula varia de 40 a $50 \mathrm{~nm}$ de diâmetro (3).

Os 9.500 nucleotídeos do VHC estão agrupados em uma região aberta de leitura (ORF - open reading frame) que é responsável por codificar as proteínas estruturais. A região do core é responsável pela formação do nucleocapsídeo; as proteínas E1, E2 e p7 são responsáveis pela montagem e a entrada do vírus na célula hospedeira. As proteínas não estruturais (NS) NS2, NS3, NS4A, NS4B, NS5A e NS5B são responsáveis pela replicação viral no hospedeiro. No ponto $5^{\prime}$ há a presença do sítio interno de entrada ribossomal (IRES), onde ocorre tradução do RNA viral (4). Cada proteína codificada pelo VHC possui uma função específica (Quadro 1).

De acordo com a Organização Mundial da Saúde (OMS), 71 milhões de indivíduos estão infectados com o VHC, sendo que no ano de 2016 foram registrados em torno de 399.000 óbitos em decorrência da evolução da doença (8).

De 1999 a 2019 foram notificados, no Brasil, 384.284 casos de hepatite C com antiVHC e/ou VHC-RNA reagente. Considerando os casos que possuíam ambos os marcadores antiVHC e VHC-RNA reagentes, foram notificados 186.019 casos (9)
O VHC possui uma alta diversidade genética, come 6 genótipos determinantes (elencados de 1 a 6), com mais de 90 subtipos. Esta identificação de genótipos é importante para a escolha do tratamento adequado e eficaz (10). Os genótipos mais prevalentes no mundo são 1, 2 e 3 . No Brasil, os mais encontrados na população infectada são $1 \mathrm{a}, 1 \mathrm{~b}, 2 \mathrm{a}$, $2 b$ e 3 (3).

Além do Brasil, os genótipos1a, 1b, 2a, 2b, 3a são encontrados na Europa ocidental e Estados Unidos. Entretanto, o 3 é mais comum na Índia, Bangladesh e outras regiões da Ásia. No norte da África e no Oriente Médio, o genótipo 4 é o mais prevalente, os genótipos 5 e 6 são encontrados em regiões da África do Sul e Ásia, respectivamente (11).

Quadro 1. Funções das proteínas no Virus da Hepatite $\mathrm{C}$ (VHC).

\begin{tabular}{|c|c|}
\hline $\begin{array}{l}\text { Proteina } \\
\text { viral }\end{array}$ & Função \\
\hline Core & $\begin{array}{l}\text { Forma o capsídeo viral, regula tradução, } \\
\text { replicação do RNA do VHC (5). }\end{array}$ \\
\hline E1 & $\begin{array}{l}\text { Entrada do VHC na célula hospedeira, adsorção, } \\
\text { endocitose (6). }\end{array}$ \\
\hline E2 & $\begin{array}{l}\text { Entrada do VHC na célula hospedeira, adsorção } \\
\text { endocitose (6). }\end{array}$ \\
\hline p7 & $\begin{array}{l}\text { Montagem VHC e formação das partículas virais } \\
\text { infecciosas ( } 7) \text {. }\end{array}$ \\
\hline NS2 & $\begin{array}{l}\text { Montagem e clivagem da poliproteína precursora } \\
\text { entre NS2 e NS3 }(5,6) \text {. }\end{array}$ \\
\hline NS3 & Helicase, cliva as proteínas não estruturais $(5,6)$. \\
\hline NS4A & $\begin{array}{l}\text { Formação da membrana do reticulo } \\
\text { endoplasmático durante a replicação viral }(5,6) \text {. }\end{array}$ \\
\hline NS4B & Cofator de protease NS3 e NS4A $(5,6)$. \\
\hline NS5A & $\begin{array}{l}\text { Região importante na sensibilidade ao INF, } \\
\text { importante para a atuação INF- } \alpha(5,6) \text {. }\end{array}$ \\
\hline NS5B & Replicação do genoma VHC $(5,6)$. \\
\hline
\end{tabular}

*NS = Proteínas não estruturais 
O fluxo de detecção do VHC inicia-se com triagem por meio do teste rápido, exames sorológicos e determinação do material genético por meio da técnica de Reação em Cadeia da Polimerase (PCR) (12).

O VHC pode ser transmitido por meio de fluidos contaminados, durante o compartilhamento de objetos de uso individual, compartilhamento de seringas por usuários de drogas, acidentes com perfuro-cortantes, em relações sexuais sem preservativos e por transfusão de sangue contaminado (13). A população deve ser orientada sobre como se prevenir contra a hepatite c, pois alguns costumes são determinantes para transmissão da doença. Os indivíduos devem evitar o sexo desprotegido, compartilhamento de objetos pessoais e seringas, pois ainda não há vacina contra o VHC (14).

A busca por tratamentos que apresentem maior efetividade e segurança e com menores efeitos adversos tem sido os maiores obstáculos que os pesquisadores enfrentam (15).

Dessa forma, o objetivo do presente trabalho foi realizar uma revisão bibliográfica atualizada sobre os fármacos preconizados no Brasil para o tratamento da hepatite $\mathrm{C}$, demonstrando os mecanismos de ação e possíveis reações adversas.

\section{MÉTODO}

Trata-se de uma revisão bibliográfica mediante levantamentos de artigos científicos, portarias e boletins do Ministério da Saúde publicados entre os anos 1975 e 2020. O levantamento bibliográfico foi realizado por meio de consulta em bases de dados de relevância de conhecimento em saúde: PubMed, "Scientific Electronic Library Online" (SciELO) e Google Academics, LILACS, com as palavras-chaves "Hepatite C" (Hepatitis C), "Tratamento" (Treatment) e "Vírus da hepatite C" (Hepatitis C virus).

Os estudos pertinentes sobre o tema foram selecionados e incluídos segundo os critérios de inclusão: disponíveis na íntegra em língua portuguesa ou inglesa, descrição sobre o mecanismo de ação dos fármacos utilizados no tratamento da hepatite $\mathrm{C}$ e suas possíveis reações adversas. Os critérios adotados para exclusão foram: resumos em anais de congressos, monografias, dissertações, teses e publicações em outros idiomas. Por fim, após análise do material selecionado, foi realizada a síntese do material e compilação dos dados de forma exploratória e descritiva.

\section{RESULTADOS E DISCUSSÃO}

Na década de 1980, o interferon-alfa recombinante começou a ser utilizado para o tratamento da hepatite $C$, até então conhecida como hepatite não-A não-B, antes mesmo de identificarem o VHC por meio de um projeto piloto no National Institute of Health, dos Estados Unidos da América (EUA), em 1986. Entretanto, sua resposta virológica sustentável (RVS) diminuía bastante após a suspensão do tratamento e possuía diversas reações adversas severas, tendo alto risco de aumentar novamente a carga viral. Além disso o período de tratamento era muito prolongado (16).

A ribavirina é um pró-fármaco sintético análogo da guanosina, atuante em uma diversidade de vírus, inclusive VHC. A ribavirina, em associação com interferon, apresentou uma RVS muito mais efetiva do que os fármacos separado; entretanto, não apresentava uma RVS efetiva em todos os genótipos, sendo mais eficiente no 2 e $3(17,18)$.

Posteriormente, o interferon alfa foi modificado, sendo inserido um revestimento com polietilenoglicol (PEG), causando a peguilação do fármaco e surgindo, assim, o interferon-alfa peguilado. Com a peguilação, a farmacocinética e farmacodinâmica do fármaco foram modificadas, aumentando a meia vida e o intervalo entre administrações, prolongando sua metabolização (19). Sua associação com a ribavirina foi considerada, por um tempo, como a terapia padrão ouro para o tratamento da hepatite $C(20)$.

Em 2011, o uso do boceprevir e telaprevir para o tratamento da hepatite $\mathrm{C}$ foi aprovado EUA, iniciando assim a primeira geração dos inibidores de protease, que tem como alvo farmacológico as proteases serina NS3/4 do VHC. Esses compostos inibem a clivagem das proteases nas suas formas maduras evitando assim a replicação viral (21).

Em 2015, chegou ao Brasil a segunda geração dos inibidores de protease: daclatasvir, sofosbuvir e 
simeprevir. Os fármacos da segunda geração possibilitaram uma terapia que abrangesse um maior número de genótipos (22). Ainda em 2015, a Agência Nacional de Vigilância Sanitária (Anvisa) autorizou o uso de ombistavir, veruprevir e ritonavir+dasabuvir para o tratamento da infecção pelo VHC (23). E em 2017, os antivirais elbasvir e grazoprevir (24).

Os mais recentes fármacos antivirais aprovados pela Anvisa foram o glecaprevir associado com pibrentasvir, velpastavir e voxilaprevir, cada um com mecanismo de ação e genótipos específicos. O voxilaprevir, aprovado em 2017 pela Food and Drug Administration (FDA), só fez parte da Comissão Nacional de Incorporação de Tecnologias (CONITEC) e disponibilizado pelo SUS até 2018 (22).

A terapia medicamentosa para hepatite $\mathrm{C}$ no Brasil está de acordo com Protocolo Clínico e Diretrizes Terapêutico (PCDT) para Hepatite C e coinfecção de 2019. Depois do diagnóstico e identificação do genótipo viral, os fármacos antivirais preconizados pelo PCDT são: alfapeguinterferon, ribavirina, sofosbuvir, ledipasvir/sofosbuvir, elbasvir/grazoprevir, glecaprevir/pibrenstavir, velpatasvir/sofosbuvir, alfaepoetina e filgrastim.

$\mathrm{O}$ esquema terapêutico contra hepatite $\mathrm{C}$ é escolhido após avaliação de alguns determinantes como genótipo viral, idade do paciente e tratamento prévio (25). O protocolo inclui fármacos imunoestimulantes, antivirais, antianêmicos e anti-neutrópicos. Nessa revisão, abordados os fármacos que atuam direta ou indiretamente contra o VHC, preconizados atualmente pelo PCDT de 2019, para hepatite C (25).

\section{Fármacos Imunoestimulantes}

Imunoestimulantes são proteínas responsáveis pela defesa do organismo contra infecções. No tratamento da hepatite $\mathrm{C}$ há o interferon, pertencente à família de citocinas endógenas com a função de modular elementos do sistema imunológico na defesa contra o VHC (26).

Interferon. É uma citocina fabricada pelas células, que estimula a atividade de diversos componentes do sistema imunológico, intensificando a capacidade do próprio organismo em combater a infecção viral (26). É classificado em dois tipos: I e II. Os de tipo I são divididos em $\alpha$ e $\beta$. São mais estáveis em meio ácido. O INF $\alpha$ é produzido nos leucócitos e o INF $\beta$ é produzido nos fibroblastos. Os INF tipo II são denominados de INF $\gamma$, se apresentam mais instáveis em meio ácido e são estimulados pelos linfócitos T (27).

Quando o interferon se liga aos seus respectivos receptores dá início a uma cascata de reações intracelulares, ativando a fosforilação de resíduos de tirosina-quinase e JAK, ocorrendo a transfosforilação dos receptores. O receptor INFAR, depois de fosforilado, se liga a Stat1 (transdutores de sinal e ativadores de transcrição) e Stat2 que irão acionar diversas proteínas imunomoduladoras antivirais (28).

$\mathrm{O}$ alfapeguinterferon $2 \mathrm{a}$, associado à ribavirina, é utilizado no tratamento da hepatite $\mathrm{C}$ crônica em pacientes com idade entre 3 e 11 anos. Pacientes com genótipos 2 e 3 são tratados por 24 semanas e com genótipos 1, 4, 5, 6 por 48 semanas (25).

Os principais efeitos adversos do interferon são cefaleia, mialgia, fadiga, náuseas, calafrios, falsa gripe, supressão da medula óssea e anemia hemolítica. Uma reação adversa que merece atenção é o efeito cognitivo emocional, ou seja, pode causar depressão; portanto, é importante o uso de antidepressivos associado a terapia contra o VHC (29).

\section{Fármacos Antivirais Análogos a Nucleosídeos}

Fármacos com estruturas análogas a guanosina, sendo um nucleosídeo sintético que interfere no processo de replicação viral. Atuam como fármacos antimetabólicos agindo na síntese do RNA mensageiro do VHC (30).

Ribavirina. É um pró-fármaco análogo da guanosina, utilizada na terapia contra VHC. Em associação com outros fármacos, aumenta a RVS, sendo utilizado no tratamento que envolve todos os genótipos do $\mathrm{VHC}$ (30).

Após o metabolismo da ribavirina, há ação no RNA viral por meio da depleção intracelular do trifosfato de guanosina, com bloqueio direto da monofosfato de iosina desidrogenase, do término da síntese do RNA mensageiro viral e da inibição direta da RNA polimerase viral (31). Consequentemente, impede a replicação do vírus ou promove construção de vírus deficientes (32). 
A ribavirina é rapidamente absorvida após administração, com tempo de concentração máxima de 2 horas após administração. Para ser ativada, a ribavirina é fosforilada pela adenosina quinase. Sua excreção ocorre por via renal (33).

A gravidez não é indicada para mulheres em tratamento com ribavirina por um período de seis meses devido sua ação teratogênica, assim como lactantes, cardiopatas e indivíduos com disfunção hepática ou anemia, devem evitar o uso desse fármaco (34).

\section{Fármacos Antivirais de Ação Direta}

Antivirais de ação direta (DAA) atuam especificamente nas proteínas virais do VHC tendo, como alvo específico, proteínas responsáveis pelo processo de replicação viral (35).

Daclatasvir. É um antiviral de ação direta, que pode ser utilizado em combinação com outros fármacos contra o VHC dos genótipos 1 e 3 . Foi o primeiro fármaco utilizado com eficácia e segurança no tratamento da hepatite C genótipo 3 (36). Seu mecanismo de ação envolve a fosfoproteína não estrutural NS5A, importante no complexo de replicação viral. Por meio de processos de fosforilação e hiperfosforilação, o fármaco modula a montagem de partículas infecciosas do VHC com bloqueio da proteína viral NS5A (37).

As principais reações adversas associadas ao daclatasvir são: fadiga, cefaleia, náusea, diarreia, anemia, neutropenia, fortes dores nas articulações, fraqueza muscular e inchaços nos gânglios (25).

Sofosbuvir. É um pró-fármaco e precisa ser metabolizado para obter sua forma ativa. É um DAA indicado para os genótipos $1,4,5$ e 6 do VHC, podendo ser utilizado em combinação com outros antivirais (38)

Por ser um análogo de nucleotídeo, seu mecanismo de ação envolve a inibição seletiva da polimerase do VHC, atuando na região NS5B do genoma viral. Após a biotransformação, o sofosbuvir se insere no RNA do VHC impedindo a replicação do vírus (39). Os efeitos adversos do sofosbuvir podem ser fadiga, cefaleia, insuficiência renal e alteração da lipase, interferindo na quebra de gordura oriunda da alimentação (40).
Ledipasvir. É utilizado associado com o sofosbuvir e considerado de primeira linha no tratamento dos genótipos 1a, 1b, 4a, 5a e 6a. O Ledipasvir age inibindo a proteína não estrutural NS5A, por meio da hiperfosforilação da proteína que é importante para replicação do RNA e montagem do VHC (41)

Os efeitos adversos mais comuns deste fármaco são fadiga, dor de cabeça, náuseas, diarreia, constipação, dispepsia, dor abdominal, boca seca, irritabilidade, astenia, redução de apetite, mialgia, tontura, problema de memória, insônia, ansiedade, depressão, distúrbio do sono, erupção cutânea e prurido (25).

Elbasvir. É um antiviral com uma alta eficácia e uma notável RSV, utilizado em associação para os genótipos 1a, 1b e 4 (38). Exerce sua ação inibindo a protease NS5A, que atua formando complexo de replicação com diversos componentes do VHC, inibindo a replicação do vírus e sua montagem (42).

A administração é por via oral, sendo que a concentração máxima é atingida em aproximadamente 3 horas (43). Os efeitos adversos que podem ocorrer com o uso do elbasvir são fadiga, cefaleia, dor abdominal, acidente isquêmico transitório e anemia (44).

Grazoprevir. É utilizado em associação com elbasvir, podendo ser utilizado junto ou não a ribavirina, muito eficiente contra os genótipos $1 \mathrm{a}, 1 \mathrm{~b}$ e 4 do VHC (24). Atua como inibidor de protease, tento como alvo a proteína NS3/4A, agindo nas enzimas fundamentais para replicação do VHC.

A metabolização do grazoprevir se dá pela via oxidativa mediada pelo citocromo P (CIP) e sua maior parte é eliminada nas fezes (45). Os efeitos adversos podem ser fadiga, dor de cabeça, náuseas, anemias e pirexia (25).

Glecaprevir. É utilizado associado com o pibrentasvir, atuando contra os genótipos 1, 2, 3, 4, 5 e 6 do VHC (22). Desempenha a função de inibidor de protease, tendo como alvo a protease NS3/4A. Tem atividade de clivagem proteolítica de proteínas multifuncionais, essenciais para a replicação do vírus, consequentemente inibindo este processo

A metabolização deste fármaco ocorre via CIP e sua excreção é, em sua maioria, fecal e menos de $1 \%$, pela urina (46). Dentre as reações adversas apresentadas estão: dores de cabeça, fadiga, náusea 
e prurido, sendo consideradas mais leves do que as de outros fármacos de ação direta (25).

Pibrentasvir. O pibrentasvir atua inibindo a fosfoproteína NS5A, que tem o papel importante na inibição da replicação viral, por dificultar a montagem e maturação de proteínas virais. O pibrentasvir também é um DAA que é eliminado pelas fezes (47).

Por ser utilizado associado ao glecaprevir, demostrou eficácia contra VHC com uma RSV de $96 \%$, atuando contra os genótipos 1 a 6 (48). Pibrentasvir apresenta as seguintes reações adversas: dores de cabeça, fadiga, náusea e prurido (25).

A associação do glecaprevir e pribentasvir foi o primeiro medicamento pangenótico para o tratamento da hepatite $\mathrm{C}$, podendo ser utilizado no tratamento de todos os genótipos do VHC, por bloquear duas proteínas essenciais para a multiplicação do VHC (22).

Velpastavir. O velpastavir é utilizado em associação com sofosbuvir para o tratamento da hepatite C. É um DAA de segunda geração, com uma resistência maior que os anteriores e apresentando uma elevada eficiência no tratamento e utilizado nos genótipos 1, 2, 3, 4, 5 e 6 do VHC. No Brasil, esta terapia foi aprovada pela Anvisa em junho de 2018, na forma farmacêutica comprimidos (22).

Velpastavir atua na proteína não estrutural NS5A, competindo no domínio I com RNA viral, consequentemente, dificultando a replicação viral e sua montagem. Sua excreção ocorre principalmente pelas fezes (49).

Este fármaco pode promover reações adversas como: dor de cabeça, fadiga, náusea, astenia e insônia, que são reações adversas leves que não provocam a interrupção do tratamento (22). Assim como a associação do glecaprevir e pribentasvir, a associação entre sofosbuvir e velpastavir tornou o medicamento pangenótico para o tratamento da hepatite $\mathrm{C}$, também utilizado em todos os genótipos do VHC, por meio do bloqueio de duas proteínas responsáveis pela multiplicação do $\mathrm{VHC}$ (25).

No quadro 2 estão representados os mecanismos de ação dos fármacos antivirais e as reações adversas mais comuns, assim como os genótipos relacionados.

Quadro 2. Mecanismo de ação dos fármacos antivirais preconizados para o tratamento da hepatite $\mathrm{C}$ de acordo com Protocolo Clínico e Diretrizes Terapêuticas, 2019 e possíveis reações adversas.

\begin{tabular}{|c|c|c|c|}
\hline Fármaco & Mecanismo de ação & Genótipos & Reações Adversas \\
\hline Interferon & Modulação do sistema imunológico contra o VHC (26) & 2 e $3(26)$ & $\begin{array}{l}\text { Falsa gripe, supressão da medula óssea, } \\
\text { anemia hemolítica, depressão, cefaleia, } \\
\text { mialgia, fadiga, náuseas e calafrio (29) }\end{array}$ \\
\hline Ribavirina & Inibição direta da RNA polimerase viral (31) & $\begin{array}{l}1,2,3,4,5 \text { e } \\
6(31)\end{array}$ & Teratogênico e disfunção hepática (34) \\
\hline Daclastavir & $\begin{array}{l}\text { Modulação da montagem de partículas infecciosas do VHC } \\
\text { por meio de bloqueios da proteína viral NS5A (37) }\end{array}$ & 1 e $3(37)$ & $\begin{array}{l}\text { Fadiga, cefaleia, náuseas, anemia e } \\
\text { fraqueza muscular (25) }\end{array}$ \\
\hline Sofosbuvir & $\begin{array}{l}\text { Inibição seletiva da polimerase do VHC, atuando na região } \\
\text { NS5B do genoma viral (39) }\end{array}$ & $1,4,5$ e $6(39)$ & $\begin{array}{l}\text { Fadiga, cefaleia, insuficiência renal e } \\
\text { alteração da lipase }(40)\end{array}$ \\
\hline $\begin{array}{l}\text { Ledispavir/ } \\
\text { Sofosbuvir }\end{array}$ & $\begin{array}{l}\text { Inibição da proteína não estrutural NS5A, impedindo a } \\
\text { replicação do RNA e montagem do VHC (41) }\end{array}$ & $\begin{array}{l}1 a, 1 b, 4 a \text { e } 5 a \\
(42)\end{array}$ & $\begin{array}{l}\text { Cutânea, astenia, mialgia, redução do } \\
\text { apetite, insônia e ansiedade (25) }\end{array}$ \\
\hline $\begin{array}{l}\text { Elbasvir/ } \\
\text { Grazoprevir }\end{array}$ & $\begin{array}{l}\text { Inibição da protease, tendo como alvo as proteínas NS5A } \\
\text { e NS3/4A, inibindo a replicação do vírus e sua montagem } \\
(42,45)\end{array}$ & $\begin{array}{l}1 \mathrm{a}, 1 \mathrm{~b} \text { e } 4 \\
(24,39)\end{array}$ & $\begin{array}{l}\text { Cefaleia, fadiga, anemia e náuseas } \\
(25,44)\end{array}$ \\
\hline $\begin{array}{l}\text { Glecaprevir/ } \\
\text { Pibrentasvir }\end{array}$ & $\begin{array}{l}\text { Inibidor de protease, tendo como alvo a protease NS5A e } \\
\text { NS3/4A, dificultando a montagem e maturação de proteínas } \\
\text { virais ( } 47 \text { ) }\end{array}$ & $\begin{array}{l}1,2,3,4,5 \text { e } 6 \\
(25,49)\end{array}$ & Cefaleia e náuseas (25) \\
\hline $\begin{array}{l}\text { Velpastavir/ } \\
\text { Sofosbuvir }\end{array}$ & $\begin{array}{l}\text { Competição pelo domínio I com RNA viral, atuando na } \\
\text { proteína não estrutural NS5A, dificultando a replicação viral } \\
\text { e sua montagem (49) }\end{array}$ & $\begin{array}{l}1,2,3,4,5 \text { e } \\
6(25)\end{array}$ & $\begin{array}{l}\text { Náuseas, astenia, insônia e cefaleia } \\
\text { (25) }\end{array}$ \\
\hline
\end{tabular}


O tratamento com interferon e/ou ribavirina pode ocasionar alterações laboratoriais, além de possíveis reações adversas. Sendo assim, necessitam de monitoramento clínico e laboratorial mais rigoroso, a fim de que aumente a adesão ao tratamento e ocorra uma adequação das doses.

Os novos DAA cursam com menor número de eventos adversos. Entretanto, todos os medicamentos utilizados no tratamento da hepatite $\mathrm{C}$ merecem um acompanhamento rigoroso e obrigatório, no sentido de se monitorar o surgimento dos eventos adversos.

\section{CONCLUSÃO}

Com o avanço da ciência e das pesquisas de novas moléculas, por meio do planejamento racio- nal e modificações moleculares, novos fármacos foram criados e incluídos na terapia medicamentosa da hepatite C. Essas melhorias moleculares visam diminuir o tempo de tratamento, aumentando assim a adesão do paciente. O aumento da adesão, também se dá, pela administração por via oral e pelo fato desses novos medicamentos apresentarem efeitos adversos mais leves.

A tendência da indústria farmacêutica, no que diz respeito ao tratamento da hepatite $\mathrm{C}$, é produzir medicamentos pangenotípicos, ou seja, que atuam em todos os genótipos do VHC. Os primeiros DAA necessitam de uma detecção prévia do genótipo, uma vez que estes fármacos antivirais atuam em genótipos específicos. Entretanto, a escolha do esquema terapêutico ainda depende de critérios clínico-laboratoriais.

\section{REFERÊNCIAS}

1. ICTV. International Committee on Taxonomy of Viruses. Hepatitis C virus. Disponível em: https://talk.ictvonline. org/ictv-reports/ictv_online_report/positive-sense-rnaviruses/w/flaviviridae\#Citation. [acesso em 20/01/2020].

2. Westbrook RH, Dusheiko G. Natural history of hepatitis C. J Hepatol. 2014;61(1 Suppl):S58-68. DOI: 10.1016/j. jhep.2014.07.012

3. Soares CC, Niel CMG, Mello FCA, Gomes AS. Hepatites Virais. In: Santos NOS, Romanos MTV, WIGG MD. Virologia Humana 3 ed. Rio de Janeiro, Guanabara Koogan Ltda; 2015 p. Rio de Janeiro: 2015. 911-927.

4. Cristina J, Colina R. Evidence of structural genomic region recombination in Hepatitis $\mathrm{C}$ virus. Virol J. 2006; 3(53):1-8. DOI: 10.1186/1743-422X-3-53

5. Alvisi G, Madan V, Bartenschlager R. Hepatitis C virus and host cell lipids: an intimate connection. RNA Biology. 2011;8(2):258-269. DOI: 10.4161/rna.8.2.15011

6. Lemm JA, O'Boyle II D, Liu M, Nower PT, Colonno R, Deshpande MS, Snyder LB, Martin SW, St. Laurent DR, Serrano-Wu MH, Romine JL, Meanwell NA, Gao M. Identification of hepatitis C virus NS5A inhibitors. J. Virol. 2010;84(1):482-491. DOI: 10.1128 / JVI.01360-09

7. Gao L, Aizaki H, He JW, Lai MM. Interactions between viral nonstructural proteins and host protein hVAP-33 mediate the formation of hepatitis $\mathrm{C}$ virus RNA replication complex on lipid raft. J Virol. 2004;78(7):3480-3488. DOI: 10.1128/jvi.78.7.3480-3488.2004

8. WHO. Global Hepatitis Report, World Health Organization. p. 12-18, 2020. Disponível em: https:// www.who.int/hepatitis/publications/global-hepatitisreport2017/en/ Acesso em: 17/09/2020.

9. BRASIL. Boletim Hepatites Virais 2020. Brasilia: Ministério da Saúde.2020. Disponível em: http://www. aids.gov.br/pt-br/pub/2020/boletim-epidemiologicohepatites-virais-2020. Acesso em: 20/12/2020.

10. Simmonds P, Becher P, Bukh J, Gould EA, Meyers G, Monath T, Muerhoff S, Pletnev A, Rico-Hesse R, Smith DB, Stapleton JT, ICTV Report Consortium. ICTV Virus Taxonomy Profile: Flaviviridae. J Gen Virol. 2017;98(1):2-3. DOI: 10.1099/jgv.0.000672

11. Martins T, Narciso-Schiavon JL, Schiavon L. Epidemiology of hepatitis C virus infection. Rev Assoc Med Bras. 2011;57(1):107-112. DOI: 10.1590/s010442302011000100024

12. BRASIL. Protocolo Clínico e Diretrizes Terapêuticas, Hepatite C, Hepatites Virais. Agência Nacional de Vigilância Sanitária. 2019. Disponível em: http:// www.aids.gov.br/pt-br/pub/2017/protocolo-clinicoe-diretrizes-terapeuticas-para-hepatite-c-coinfeccoes. Acesso em: 12/09/2020.

13. Alter MJ. Prevention of spread of hepatitis C. Hepatology. 2002;36(5 Suppl 1):S93-98. DOI: 10.1053/ jhep.2002.36389

14. BRASIL. A, B, C, D, E de Hepatites para Comunicadores. Brasília; Ministério da Saúde. 2005. Disponível em: https://bvsms.saude.gov.br/bvs/publicacoes/hepatites abcde.pdf. Acesso em: 15/08/2020. 
15. Perlin CM, Groto AD, Perlin GO, Salamanca MAB. Hepatite C: Revisão dos medicamentos utilizados no tratamento. Rev. Med. São Paulo. 2019;98(5):341-348. DOI: $10.11606 /$ issn.1679-9836.v98i5p341-348

16. Chutaputti A. Adverse effects and other safety aspects of the hepatitis C antivirals. J Gastroenterol Hepatol. 2000;15(Suppl:E):156-163. DOI: 10.1046/j.1440-1746. 2000.02114.x

17. Simon DM, Gordon SC, Kaplan MM, Koff RS, Regenstein F, Everson G, Lee YM, Weiner F, Silverman A, Plasse T, Fedorczyk D, Liao MJ. Treatment of chronic hepatitis $\mathrm{C}$ with interferon alfa?n3: A multicenter, randomized, open-label. Hepatology. 1997;25(2):445-448. DOI: 10.1002/hep.510250232

18. Tong MJ, Blatt LM, McHutchison JG, Co RL, Conrad A. Prediction of response during interferon alfa $2 \mathrm{~b}$ therapy in chronic hepatitis $\mathrm{C}$ patients using viral and biochemical characteristics: a comparison. Hepatology. 1997;26(6):1640-1645. DOI: 10.1002/hep.510260637

19. Bailon P, Berthold W. Polyethylene glycol-conjugated pharmaceutical proteins. PSTT. 1998;1(8):352-356. DOI: $10.1016 / \mathrm{S} 1461-5347(98) 00086-8$

20. Diago M, Shiffman ML, Bronowicki JP, Zeuzem S, Rodriguez-Torres M, Pappas SC, Tietz A, Nelson DR. Identifying hepatitis $C$ virus genotype $2 / 3$ patients who can receive a 16 -week abbreviated course of peginterferon alfa-2a (40KD) plus ribavirin. Hepatology. 2010;51(6):1897-903. DOI: 10.1002/hep.23531

21. Bersusa AAS, Bonfim JRA, Louvison MCP. Inibidor de protease NS3/4 (boceprevir e telaprevir) associado a alfapeginterferona e ribavirina no tratamento de adultos com hepatite viral C crônica de genótipo 1. Parecer técnico-científico do Instituto de Saúde. São Paulo. 2012;14(2): 221-228.

22. BRASIL. Glecaprevir em associação a pibrentasvir para o tratamento de hepatite C crônica. 2018. Agência Nacional de Vigilância Sanitária. Disponível em: http:// conitec.gov.br/images/Consultas/2018/Relatorio_Gleca previrPibrentasvir_HepatiteCCr onica_CP23_2018.pdf. Acesso em 20/03/2020.

23. BRASIL. Veruprevir, ritonavir, ombitasvir e dasabuvir para o tratamento de hepatite C crônica causada por infecção pelo genótipo 1 do HCV. 2016. Agência Nacional de Vigilância Sanitária. Disponível em: http:/conitec.gov.br/images/Relatorios/2016/Relatorio_ ViekiraPak_HepatiteC_Recomendacao.pdf. Acesso em 24/04/2020.

24. BRASIL. Novos tratamentos para hepatite C. 2017. Agência Nacional de Vigilância Sanitária. Disponível em: http://portal.anvisa.gov.br/noticias/-/asset_publisher/ FXrpx9qY7FbU/content/novos-tratamentos-parahepatite-c/219201. Acesso em 22/03/2020.

25. BRASIL. Protocolo clínico e diretrizes terapêuticas para hepatite c e coinfecções. Ministério da Saúde. Secretaria de Vigilância em Saúde. p. 13-18 1ª ed., 2019. Disponível em: http://bvsms.saude.gov.br/bvs/publicacoes/ protocolos_diretrizes_hepatite_viral_c_coinfeccoes.pdf. Acesso em 28/03/2020.

26. Acras RN, Pedroso MLA, Caum LC, Pisani JC, Amarante HMBS, Carmes Eliane R. A taxa de resposta sustentada da hepatite $\mathrm{C}$ crônica ao tratamento com os diversos interferons-alfa e ribavirinas distribuídos pelo governo brasileiro é semelhante à da literatura mundial. Arq. Gastroenterol. 2004;41(1):3-9. DOI: 10.1590/S000428032004000100002

27. Langer JA. Interferon at 50: new molecules, new potential, new (and old) questions. Sci STKE. 2007;2007(405):53. DOI: $10.1126 /$ stke.4052007pe53

28. Thitinan S, McConville JT. Interferon alpha delivery systems for the treatment of hepatitis C. Int $\mathrm{J}$ Pharm. 2009;369(1-2):121-35. DOI: 10.1016/j.ijpharm.2008. 11.027

29. Smith JP, Dong MH, Kaunitz JD. Evaluation of a pharmacist-managed hepatitis $\mathrm{C}$ care clinic. Am J Health Syst Pharm. 2007;64(6):632-636. DOI: https://doi. org/10.2146/ajhp060153

30. Myers RP, Shah H, Burak KW, Cooper C, Feld JJ. An update on the management of chronic hepatitis C: 2015 Consensus guidelines from the Canadian Association for the Study of the Liver. Can J Gastroenterol Hepatol. 2015;29(1):19-34. DOI: 10.1155/2015/692408

31. Zeuzem S, Welsch C, Herrmann E. Pharmacokinetics of peginterferons. Semin Liver Dis. 2003;23(Suppl 1): 23-28. DOI: $10.1055 / \mathrm{s}-2003-41631$

32. Shepherd J, Jones J, Hartwell D, Price A, Waugh N. Interferon alfa (pegylated and non-pegylated) and ribavirin for the treatment of mild chronic hepatitis $\mathrm{C}$ : a systematic review and economic evaluation. In: NIHR Health Technology Assessment programme: Executive Summaries; 2007. Disponível em: https://www.ncbi.nlm. nih.gov/books/NBK56839/ Acesso em: 01/10/2020.

33. Glue P, Schenker S, Gupta S, Clement RP, Zambas D, Salfi M. The single dose pharmacokinetics of ribavirin in subjects with chronic liver disease. $\mathrm{Br} \mathrm{J}$ Clin Pharmacol. 2000;49(5):417-421. DOI: 10.1046/j.13652125.2000.00186.x

34. Glue P. The clinical pharmacology of ribavirin. Semin Liver Dis. 1999;19(Suppl 1):17-24.

35. Pol S, Corouge M. Traitement de l'hépatite C: état actuel et perspectives. Rev Prat. 2014;64(5):605-612

36. Borges Neto FC, Souza MGL, Novaes ICRB, Silveira VS, Nunes MP, Miranda GCBM, Moia LJMP, Barbosa MSB, Miranda ECBM. Efetividade do tratamento com drogas antivirais de ação direta em pacientes com hepatite $\mathrm{C}$ atendidos em um centro de referência no estado do Pará, Brasil, de 2017 a 2019. Rev Pan-Amaz Saude. 2020;11: e202000468. DOI: 10.5123/s2176-6223202000468 
37. Guedj J, Dahari H, Rong L, Sansone ND, Nettles RE, Cotler SJ, Layden TJ, Uprichard SL, Perelson AS. Modeling shows that the NS5A inhibitor daclatasvir has two modes of action and yields a shorter estimate of the hepatitis $\mathrm{C}$ virus half-life. Proc Natl Acad Sci USA. 2013;110(10):3991-3996. DOI: 10.1073/ pnas. 1203110110

38. Harper S, McCauley JA, Rudd MT, Ferrara M, DiFilippo M, Crescenzi B, Koch U, Petrocchi A, Holloway MK, Butcher JW, Romano JJ, Bush KJ, Gilbert KF, McIntyre CJ, Nguyen KT, Nizi E, Carroll SS, Ludmerer SW, Burlein C, DiMuzio JM, Graham DJ, McHale CM, Stahlhut MW, Olsen DB, Monteagudo E, Cianetti S, Giuliano C, Pucci V, Trainor N, Fandozzi CM, Rowley M, Coleman PJ, Vacca JP, Summa V, Liverton NJ. Discovery of MK-5172, a Macrocyclic Hepatitis C Virus NS3/4a Protease Inhibitor. ACS Med Chem Lett. 2012;3(4): 332-336. DOI: $10.1021 / \mathrm{ml} 300017 \mathrm{p}$

39. Eltahla AA, Luciani F, White PA, Lloyd AR, Bull RA. Inhibitors of the Hepatitis C Virus Polymerase; Mode of Action and Resistance. Viruses. 2015;7(10):5206-5224. DOI: $10.3390 / \mathrm{v} 7102868$

40. Bhatia HK, Singh H, Grewal N, Natt NK. Sofosbuvir: A novel treatment option for chronic hepatitis $\mathrm{C}$ infection. J Pharmacol Pharmacother. 2014;5(4):278-284. DOI: 10.4103/0976-500X.142464

41. Bagaglio S, Uberti-Foppa C, Morsica G. Resistance Mechanisms in Hepatitis C Virus: implications for Direct-Acting Antiviral Use. Drugs. 2017;77(10): 1043-1055. DOI: 10.1007/s40265-017-0753-x.

42. Maekawa S., Enomoto N. Viral Variation and Response to Therapy. In: Miyamura T., Lemon S., Walker C., Wakita T. (eds) Hepatitis C Virus II. Tokio: Springer; 2016. 243-256 DOI: 10.1007/978-4-431-56101-9_9
43. Bell AM, Wagner JL, Barber KE, Stover KR. Elbasvir/ Grazoprevir: A Review of the Latest Agent in the Fight against Hepatitis C. Int J Hepatol. 2016;2016:3852126. DOI: $10.1155 / 2016 / 3852126$

44. Lawitz EJ, Dvory-Sobol H, Doehle BP, Angela S. Clinical Resistance to Velpatasvir (GS-5816), a Novel Pan-Genotypic Inhibitor of the Hepatitis C Virus NS5A Protein. Antimicrob. Ag. and Chemother. 2016;60(9):5368-5378. DOI: 10.1128/AAC.00763-16

45. Zeuzem S, Ghalib R, Reddy KR, Pockros PJ, Ari ZB, Zhao Y, Brown DD, Wan S, DiNubile MJ, Nguyen B, Robertson MN, Wahl J, Barr E, Butterton JR. Grazoprevir-Elbasvir Combination Therapy for Treatment-Naive Cirrhotic and Noncirrhotic Patients With Chronic Hepatitis C Virus Genotype 1, 4, or 6 Infection: A Randomized Trial. Ann Intern Med. 2015;163(1):1-13. DOI: 10.7326/M15-0785

46. Salam KA, Akimitsu N. Hepatitis C virus NS3 inhibitors: current and future perspectives. Biomed Res Int. 2013;2013:467869. DOI: 10.1155/2013/467869

47. Lamb YN. Glecaprevir/Pibrentasvir: First Global Approval. Drugs. 2017;77(16):1797-1804. DOI: 10.1007/ s40265-017-0817-y

48. Ng TI, Krishnan P, Pilot-Matias T, Kati W, Schnell G, Beyer J, Reisch T, Lu L, Dekhtyar T, Irvin M, Tripathi R, Maring C, Randolph JT, Wagner R, Collins C. In Vitro Antiviral Activity and Resistance Profile of the NextGeneration Hepatitis C Virus NS5A Inhibitor Pibrentasvir. Antimicrob Agents Chemother. 2017;61(5):e02558-16. DOI: 10.1128/AAC.02558-16

49. Ascher DB, Wielens J, Nero TL, Doughty L, Morton CJ, Parker MW. Potent hepatitis C inhibitors bind directly to NS5A and reduce its affinity for RNA. Sci Rep. 2014;4765(4): 1-12. DOI: 10.1038/srep04765 